\title{
AÇÕES INFLUENTES NA AQUISIÇÃO DA ORALIDADE EM LÍNGUA JAPONESA COMO LE
}

\author{
Lincoln Ferreira de Araújo ${ }^{1}$ \\ Kyoko Sekino ${ }^{2}$
}

\begin{abstract}
Resumo: Este trabalho propõe-se a investigar ações de aprendizagem de uma sala de aula de um curso de língua japonesa, a qual possui como foco a aquisição da oralidade. Baseado em Brown (2000; 2007) e Benson (2001) dentre outros, nossa pesquisa objetiva observar a relação entre os métodos utilizados pelo professor e o desenvolvimento oral de alunos iniciantes. Por meio do método de observação direta, de questionários e de aplicação de testes orais, identificou-se que os métodos utilizados pelo professor geram efeitos tanto positivos quanto negativos. Notou-se que, ao se identificar uma dificuldade dos alunos, o professor imediatamente ajustou os seus métodos; como resultado, conduziu os alunos a aprenderem a língua alvo. Assim, verificou-se, no professor, uma variação de métodos e de técnicas em sala de aula. Ademais, notou-se que um dos fatores interessantes assistido foi a colaboração dos alunos em sala de aula, em que um ajudou o outro, auxiliando a turma adquirir a língua alvo.
\end{abstract}

Palavras-chave: Aquisição da LE; Oralidade; Métodos; Estratégias; Autonomia.

\begin{abstract}
This work proposes to investigate actions that happen in a Japanese language classroom to observe acquisition of oral skill as focus point. Based on Brown (2000; 2007), Benson (2001) and among others, our research aims to see the relationship between methods used by the teacher and beginners students' oral skill development. With such methods as direct observation, questionnaires and the application of two oral testes, we identify that the methods used by the teacher made both positive as well as negative effects. We perceived that the teacher immediately adjusted his methods, as he noticed the students' difficulty; as a result, he made them learn the target language. As it was evident, the teacher varies his methods and techniques in the classroom. Besides, one of the interesting factors is the students' collaboration in the classroom, in which one helps the other so that it made the class acquire the target language.
\end{abstract}

Keywords: Foreign language acquisition; Oral skill; Methods; Strategies; Autonomy.

1 Graduado pela Universidade de Brasília (UnB), na Licenciatura em Japonês (LET), em 2015; lincoln.fa@hotmail.com.

2 Professora Doutora na Licenciatura em Japonês (LET) na Universidade de Brasília (UnB); kyokosekino@ gmail.com. 


\section{Introdução}

O presente trabalho trata-se de um estudo exploratório, apresentado no trabalho final de curso (TCC), sobre a relação entre os métodos de aprendizagem utilizados pelo professor e o desenvolvimento da oralidade dos alunos de um curso básico de Língua Japonesa. O pressuposto da investigação é que os professores de língua estrangeira (LE) dispõem de vários métodos e técnicas para lecionarem. Porém, nem sempre, elas podem funcionar de forma a auxiliar os alunos. Antes de apresentar os resultados dos estudos, é importante comentar que neste artigo, tratamos a LE e a segunda língua (L2) sem distinção. Isso porque a língua japonesa é uma língua estrangeira a qual a maioria dos alunos falantes nativos de Português-Brasileiro aprende em instituições escolares. Segundo Ellis (1994), o termo L2 é geralmente usado para se referir a qualquer língua que não seja a primeira. Diante disso, na pesquisa utilizará ambos os termos.

A aquisição (ou não aquisição) de LE é uma discussão duradoura, devido a diferentes formas de aprendizado da língua materna (LM) (KRASHEN, 1987). Krashen (1981) distingue "Aquisição" de "Aprendizagem". Aquela é o processo subconsciente, intuitivo e natural de aprender uma língua através da interação/comunicação e exposição a ela, socialmente, através de situações reais de convívio. Aprendizagem, por sua vez, é o processo consciente (e não espontâneo) de aprender uma língua (e sua gramática) pelo seu estudo.

Verifica-se, nas literaturas, que já foram introduzidas várias hipóteses e teorias sobre o processo de aprendizagem, tais como: hipóteses behavioristas (SKINNER, 1957); hipótese de monitor e de input (KRASHEN, 1987); abordagem cognitiva (AUSUBEL, 1963; BIALYSTOK, 1978; MCLAUGHIN, 1978; ANDERSON, 1983; ELLIS, 1985); teorias de conversação (GRICE, 1975; PASK, 1975); teorias de aculturação (SCHUMANN, 1978) dentre outros. Baseado nessas hipóteses, criaramse uma variedade de métodos e técnicas para facilitar a aprendizagem da LE. Essa proliferação de métodos e técnicas reflete a complexidade da aprendizagem de LE. Ademais, há evidências que o êxito da aquisição da L2 difere para cada indivíduo, o que permitiu novos ramos de estudos, como: psicológicos, cognitivos, antropológicos e sociais. Por exemplo, quando se há a necessidade de investigar a questão de autonomia, atitudes, crenças e identidade, com ênfase na diferença individual. Esse exemplo nos remete a tendência de, no Brasil, as pesquisas relacionadas com crenças e com autonomias serem, na maioria, relatadas, em estudos de caso.

Neste estudo, nosso objetivo é observar a influência do(s) método(s) usado(s) pelo professor no ensino da oralidade dos alunos no âmbito de aquisição e aprendizagem de uma língua distinta (SHIBATANI, 2006) da LM dos alunos. Delimitou-se a um pequeno grupo de adultos iniciantes, falantes nativos de língua portuguesa brasileira, com foco na oralidade. A pesquisa partiu das seguintes perguntas: (1) Todos os métodos e técnicas utilizados, na sala de aula, geram o efeito esperado?; (2) O professor varia os métodos e técnicas em sala de aula?; (3) Quais métodos e técnicas fazem os alunos falarem a 
língua alvo?; enfim, (4) As ações conjuntas na sala de aula geram algum efeito positivo, mesmo havendo a diferença individual entre alunos?

Assim, analisaram-se as ações de aprendizagem que ocorrem em sala de aula no que diz respeito a abordagens, aos métodos e às técnicas utilizadas pelo professor. Além disso, o impacto delas sobre os alunos na aquisição da oralidade em língua japonesa. Para isso, identificaram-se os métodos e as técnicas que geraram efeitos positivos. Averiguou-se, ademais, a relação da aprendizagem da língua-alvo dos alunos iniciantes com os métodos utilizados; se houve aquisição da oralidade; qual a influência do professor sobre os alunos; e se houveram outras ações que resultaram, positivamente, na aquisição da oralidade.

\section{Revisão da literatura}

\subsection{Abordagens, métodos e técnicas do ensino de LE}

Primeiramente, esclarecer-se-á a distinção entre abordagem, método e técnica que vêm sendo difundida por algum tempo segundo os conceitos de Anthony (1963, apud BROWN, 2007, p. 14). Para o autor, abordagem, no ensino de LE, diz respeito a uma direção tomada pelo professor sobre a aplicação de uma forma de ensino. Vilaça (2008) a interpreta como uma "visão geral sobre o que seja uma língua e sobre o que seja ensinar e aprender uma língua" (p. 76). Métodos se referem a formas variadas e concretas de se aplicar a abordagem. Técnicas, por sua vez, relacionam-se a atividades realizadas pelo professor durante a aula, em que se vale de métodos a fim de propulsionar o aprendizado de seus alunos. A seguir, tratar-se-á uma síntese de cada abordagem e de cada método relevante a nossa pesquisa.

Introduzem-se duas abordagens frequentemente utilizadas no ensino de LE, são: a natural e a comunicativa. Brown (2007, p. 31) discorre que o foco da Abordagem Natural é o significado e não a forma. A oralidade é um dos pontos que pode ser mais trabalhado com essa abordagem. O professor se utilizará de expressões de fácil compreensão; de um ritmo adequado em suas enunciações. Ademais, estará sempre atento à compreensão dos alunos com intuito de que o output possa ocorrer. Percebese, nessa abordagem, uma liberdade de os alunos falarem da forma como se sentem à vontade, contanto que seja na língua alvo. Eles não têm seus erros corrigidos a todo instante - a não ser que sejam erros muito grosseiros, ou caso o aluno não consiga desenvolver a fala. $\mathrm{O}$ foco, principal, é ensinar a se expressar oralmente. A abordagem natural leva ao desenvolvimento das habilidades de fala e de compreensão, haja vista que ela ajuda para que a aquisição da língua surja da forma mais natural possível.

A Abordagem Comunicativa, por sua vez, aponta para uma visão na qual o aprendizado do aluno seja mais próximo e consistente do cotidiano. Para esse fim, o professor traz contextos reais para a sala de aula com o intuito de incentivar uma ativa participação do aluno, sem se preocupar, em demasia, com critérios gramaticais. 
Segundo Brown (2007, p. 49), a finalidade da abordagem comunicativa é a comunicação. Nela, o professor não é o detentor do conhecimento, mas sim o facilitador. Por causa disso, o professor pode dispor de quaisquer meios necessários para o desenvolvimento do aluno. Inclusive, não evita o uso da língua materna dos alunos, se for preciso. É uma abordagem que se preocupa mais com o significado do que com o sistema linguístico.

No que diz respeito aos métodos de ensino de LE, o Método Tradicional, ou seja, Método Tradução-gramática é um dos métodos fortemente usado em muitas instituições de ensino de LE. Nele, atém-se a um aprendizado inclinado a regras gramaticais e ao uso de dicionário, indispensável para entender textos em LE por meio de tradução. Constata-se que as aulas são ministradas na LM dos alunos com o eixo em vocabulários, em regras, principalmente, as gramaticais e as estruturais da língua, em vez da comunicação. O professor é detentor do conhecimento (BROWN, 2007, p. 19), diferente de seu papel na abordagem comunicativa.

O Método Audiolingual é, por sua vez, voltado à memorização de estruturas gramaticais. Esse método tem por regra não permitir erros, os quais tendem a ser extinguidos. O professor é quem detém o saber e, também, utiliza pouco da língua materna dos estudantes. Geralmente, o material didático possui predominantemente formas de diálogos, os quais alunos repetem até memorizarem. As estruturas são apresentadas enquanto se leem as frases. Quanto à gramática, ela é muito pouca explicada; em consequência, geralmente, aprendida por indução e por explicações dedutivas em aula. A pronúncia é essencial. Por isso, os erros são completamente expurgados e os acertos, geralmente, reforçados imediatamente (Brown, 2007, p. 23).

Um dos métodos opostos ao Gramática-Tradução e ao Audiolingual é o Método Direto. Nele, o professor assume o papel de detentor do saber, o qual conduz a turma para as atividades, na maioria das vezes, iniciadas por ele. Richards e Rodgers (2001, apud BROWN, 2007, p. 21) pontuaram as características desse método: as aulas são realizadas, exclusivamente, na língua-alvo, com vocabulário restrito e com caráter cotidiano, em que o professor constrói, cuidadosamente, um jogo de perguntas e respostas, visando a progressão das habilidades de comunicação do aluno. Assim, as regras e estrutura da língua acabam sendo induzidas ao aluno.

O método que conduz uma colaboração dos alunos na turma é conhecido como Community Language Learning (CLL). Nesse método, há um distanciamento da imagem de uma turma tradicional: os indivíduos, incluindo o professor, agem como um grupo, objetivando-se uma colaboração mútua. Logo, o professor conduz os alunos a atividades que deseja aplicar, ou seja, o professor assume o papel de aconselhar e de auxiliar os alunos. Os alunos, por sua vez, são os protagonistas: participam, ativamente, dos diálogos na LE e pedem ajuda dos colegas quando não sabem falar o que pretende dizer. O professor, caso nenhum colega saiba ajudar, age com intervenções (BROWN, 2007, p. 25). 
Há métodos excepcionais pela natureza como Suggestopedia (Método Sugestivo) que objetiva buscar um ambiente propício para os alunos aprenderem uma LE, reduzindo seus bloqueios (LOZANOV, 1979). Através de técnicas apropriadas, como o uso de música, atividades lúdicas e relaxamento, o filtro afetivo ${ }^{3}$ do aluno tende a baixar; consequentemente, deixá-lo menos armado para o aprendizado.

Existe, também, o Método Silencioso que busca apenas a fala dos alunos, sem nenhuma instrução verbal por parte do professor. Nele, o objetivo é promover a percepção dos alunos para que eles possam conduzir o próprio aprendizado. (CATTEGNO, 1972; BROWN, 2007, p. 29).

As abordagens, os métodos apresentados aqui, com exceção do método tradicional, têm um ponto em comum: o foco na oralidade. Para desenvolver melhor essa habilidade, os alunos e os professores dispõem de estratégias em LE a fim de potencializar sua aquisição. No tópico seguinte, trazemos uma sucinta definição do que são estratégias em LE.

\subsection{Estratégias em LE}

Brown (2000,p. 122) distingue a estratégia em três vieses no ensino/aprendizagem de LE, são: estratégias de aprendizagem, estratégias de comunicação e estratégia baseada na instrução.

Nas estratégias de aprendizado, os alunos possuem um conjunto de estratégias que são diferentes das aplicadas pelo professor. Nelas, os alunos desenvolvem habilidades metacognitivas e cognitivas que orientam seus estudos em um âmbito de autoavaliação constante e do uso dos materiais a sua disposição, como: imagens, apostilas, música etc. Não obstante, eles usam, também, de estratégias socioafetivas as quais podem resolver problemas relativos à aprendizagem, em que recorrem aos colegas, buscando uma interação social e trabalho com o intuito de auxiliar seu aprendizado.

Além disso, há situações de estratégias que os alunos utilizam durante sua fala. Observa-se uma dessas estratégias quando os alunos encerram um diálogo; então, por não conseguir desenvolvê-lo mais, recorrem a frases pré-preparadas as quais podem ser utilizadas em vários contextos. Estes tipos de estratégias são conhecidas como estratégias de comunicação (BROWN, 2000, p. 129 - 130).

O uso concomitante de várias estratégias de aprendizado e de comunicação é conhecido como estratégias baseadas em instrução. Nelas, o aluno usa tanto ações que auxiliam seu aprendizado quanto as que auxiliam sua comunicação com outros. Ações, essas, que são classificadas em dois tipos: diretas e indiretas. Nas estratégias diretas, os alunos desenvolvem ações que auxiliam a memorização, como: o uso de imagens e

3 Krashen (1987) define o filtro afetivo como parte do processo interno no qual configuram os estados emocionais, as atitudes, as necessidades, a motivação do aprendiz ao aprender uma língua, e que regula e seleciona modelos de língua a serem aprendidos, a ordem de prioridade na aquisição e a velocidade nesta aquisição. 
sons, associando-os com palavras; revisão repetida do conteúdo, em que se utilizam de gestos e de ações correlatas com o conteúdo aprendido anteriormente para que crie uma espécie de memória episódica.

No que diz respeito às estratégias indiretas, os alunos se baseiam em três tipos: Estratégias Metacognitivas, em que eles podem averiguar o seu próprio desenvolvimento, por buscar informações já conhecidas e descobrir novas informações, constantemente, as organizando em sua fala para se comunicarem. Verifica-se que mesmo que isso deixe a sua comunicação mais lenta, pode se tornar mais preciso. Estratégias de Afinidade, usam-se delas para envolver todas as ações com o intuito de minimizar sua ansiedade, melhorar seu ego. Isso com auxílio de músicas, de atividades relaxantes, de expressões faciais com sorriso, considerando seus limites físicos e mentais. Por último, Estratégias Sociais com as quais o aluno busca esclarecer suas dúvidas com a ajuda de seus colegas. A cooperação mútua permite aos alunos uma consciência não só de suas limitações, mas também das dos outros (BROWN, 2000, p. 133).

Brown (2000) acredita que tais estratégias podem estimular a autonomia do aluno em seu próprio aprendizado. Nessa perspectiva, com o intuito de esclarecer a autonomia, reservou-se um último tópico para discorrer sobre isso.

\subsection{Autonomia do aluno}

Benson (2001, p. 47) define a autonomia como "a capacidade de assumir o controle de sua própria aprendizagem", ou seja, o aluno é capaz de encontrar a melhor forma de adquirir o conhecimento, quando gerencia suas próprias ações. Benson afirma ainda que a autonomia é uma capacidade multidimensional, a qual irá assumir formas distintas dependendo de pessoas diferentes, e, até mesmo, para a mesma pessoa em diferentes contextos ou em momentos diferentes.

Para Holec (1981, apud BENSON, 2001, p. 48) autonomia é uma capacidade de desenvolver sua própria aprendizagem; assumir a responsabilidade por todas as decisões relativas a todos os aspectos dessa aprendizagem como objetivos, conteúdos, progressões, seleção de métodos, acompanhamento consciente da aprendizagem e avaliação. O aprendiz autônomo é "capaz de tomar todas essas decisões relativas à aprendizagem com a qual ele ou ela deseja se envolver".

Com isso, podemos definir a autonomia, para os fins desta pesquisa, como a administração das capacidades de aprendizagem em prol da aquisição do conhecimento pelo próprio aluno. É importante lembrar de que a autonomia está relacionada à motivação. O professor é um sujeito que pode agir como motivador dos seus alunos, tendo como meta a busca pela autonomia destes em seus estudos. 


\section{Métodos de coleta de dados}

Observou-se uma turma de nível iniciante, "Básico 1", de um curso de língua japonesa aberto para o público realizado no segundo semestre de 2015. Nela, foram observadas cinco aulas, um total de 20 horas, entre os meses de setembro e outubro. A composição da turma era de cinco alunos na faixa etária de 20 anos e um professor recém-licenciado por uma universidade federal. Todos participaram da pesquisa. Os respectivos participantes possuem a mesma LM, português-brasileiro. Os alunos responderam a questionários semiestruturados. Também, foram submetidos a dois testes orais com o objetivo de averiguar a aquisição da oralidade em japonês, aplicados um no início e outro ao final da nossa observação, o que coincidiu com o início e meio do curso. Aplicou-se, ademais, uma entrevista ao professor responsável, feita uma no primeiro dia de observação e outra no último, com o fito de arrecadarmos dados mais precisos em relação aos métodos e técnicas utilizados. Obteve-se o perfil do professor por meio de um questionário.

Os testes orais focaram-se na comunicação. Consistia de expressões e de léxicos que os participantes já tinham aprendidos. No primeiro teste, aplicou-se 15 perguntas, e no segundo, 25 perguntas, incluindo as que foram aplicadas no primeiro teste com o intuito de observar a fixação ou melhoria da habilidade oral (Vide Apêndice).

\section{Análise dos dados}

A análise de dados consistiu da triangulação dos dados recolhidos através dos questionários, das entrevistas, dos testes orais e das anotações de campo juntamente com o respaldo teórico, apresentado na seção de revisão da literatura.

As aulas da turma observada tinham como enfoque maior a oralidade dentre as demais habilidades (ler, escrever e ouvir). Assim, as atividades, comportamentos e efeitos observados foram abordados, nesta pesquisa, relacionados à habilidade oral.

Apresentar-se-á este tópico em quatro seções que tratam: 4.1. Padrão de comportamento do professor; 4.2. Ações dos alunos e do professor; 4.3. Efeitos das técnicas utilizadas pelo professor e 4.4. Desempenho dos alunos no teste oral.

\subsection{Padrão de comportamento do professor}

Durante as observações de aula, verificou-se uma série de comportamentos por parte do professor, os quais serviam como técnicas para instigar o aprendizado dos alunos. Citam-se alguns, tais como:

A - Iniciar as aulas perguntando sobre como os alunos estavam (tanto na língua alvo como na LM)

$\mathrm{B}$ - Estar sorrindo durante as aulas 
C - Fazer brincadeiras com os alunos, utilizando-se do conteúdo estudado

D - Instigar os alunos a pensarem

E - Parabenizar os alunos por seu progresso

O comportamento 'A' constata-se, nas observações, quando o professor, em sala de aula, sempre procurava iniciar as aulas fazendo perguntas informais a respeito da semana dos alunos e sobre seus estudos semanais de japonês. Os alunos respondiam-lhe prontamente, de forma sútil e informal. Isso serviu como uma indução a revisão da aula anterior. Os alunos traziam suas dúvidas de forma oral, habilidade, essa, que já estava presente, na sala de aula, antes mesmo de se introduzir as atividades do dia. Observa-se que o professor, ao receber seus alunos com uma conversa informal, já trabalhava com os alunos a oralidade para que se diminuísse o filtro afetivo de aprendizagem (KRASHEN; TERRELL, 1983), buscando um ambiente propício para a prática da oralidade.

Os comportamentos ' $\mathrm{B}$ ' e ' $\mathrm{C}$ ' aconteciam, na maioria das vezes, em concomitância. Esses dois comportamentos demonstram não apenas traços do perfil do professor, mas também traços do método Sugestivo de Lozanov (1979). O professor utilizou-se de atividades (técnicas) lúdicas e de relaxamento para diminuir o filtro afetivo dos alunos, induzindo-os a um estado de melhor absorção do conteúdo; logo, melhorando seu aprendizado.

O comportamento ' $D$ ' pauta-se no fato de que o professor tentava estimular os alunos a pensarem sobre as suas próprias dúvidas. Por causa disso, nota-se que o professor é bastante consciente do seu comportamento relacionado aos métodos e às técnicas utilizadas em aula. Ele respondeu na entrevista que:

...eu gosto de fazer os alunos pensarem, raciocinarem, pois, quanto mais eles fazem isso, mais eles vão conseguir desenvolver essa habilidade de raciocinar e associar o que é aquilo (conteúdo) e usá-lo em determinada situação.

Sendo assim, o comportamento ' $\mathrm{D}$ ' tem respaldo, também, em traços do método silencioso, porque o professor se abstém de falar; consequentemente, esse silêncio propicia o raciocínio do aluno a fim de ele próprio ache a resposta (RICHARDS; RODGERS, 2001).

Outro comportamento que notamos com certa ênfase é o 'E' - parabenizar os alunos por qualquer progresso. Durante a entrevista, o professor nos revelou:

...é importante elogiar. Isso faz muita diferença. Um professor não pode ficar colocando o aluno para baixo sabe, dizendo que não sabe, ou que deve estudar mais, ele precisa ajudar e elogiar quando o aluno consegue algo. Isso cria um (bom) filtro afetivo com a língua japonesa. 
Tal comportamento, juntamente com o 'B' - sorrir, é tratado por Brown (2000, p. 133) como parte da estratégia baseada em instrução, o qual, ambos, o aprendiz e/ou professor, usam-nos com o intuito de reduzir a ansiedade. Brown afirma que o uso do riso é eficaz quando o aluno progride no aprendizado.

\subsection{Ações dos alunos e professor}

Neste tópico, relata-se, como pode ser visto nas tabelas, uma lista de ações observadas durante as aulas. Algumas delas foram instigadas ou iniciadas pelo professor e outras pelos próprios alunos.

TABELA 1 - Ações realizadas em sala de aula

\begin{tabular}{|l|l|}
\hline \multicolumn{2}{|c|}{ Ações em sala de aula (Número total de aulas:20 horas) } \\
\hline \multicolumn{1}{|c|}{ Realizadas pelo PROFESSOR } & \multicolumn{1}{c|}{ Realizadas pelos ALUNOS } \\
Revisão do hiragana com cartões & $\begin{array}{l}\text { Leitura individual do vocabulário e de } \\
\text { textos da apostila }\end{array}$ \\
\hline $\begin{array}{l}\text { Utilizar gestos ou imagens para explicar } \\
\text { algo na língua alvo }\end{array}$ & $\begin{array}{l}\text { Copiar conteúdo extra ou explicações no } \\
\text { caderno }\end{array}$ \\
\hline Aplicar exercícios com áudios & Ajudar os colegas \\
\hline Aplicar atividades em duplas & Fazer perguntas na língua alvo \\
\hline Comandos na língua japonesa & $\begin{array}{l}\text { Ler e não ler uma anotação para responder } \\
\text { a questões orais }\end{array}$ \\
\hline Revisão oral do conteúdo & Leitura lenta, Oralidade rápida \\
\hline Realizar atividade de leitura de textos & Responder juntos a uma questão \\
\hline Realizar ditados & $\begin{array}{l}\text { Apresentar novas expressões em japonês } \\
\text { e explicar em português }\end{array}$ \\
\hline Aplicar atividades audiolinguais & \\
\hline $\begin{array}{l}\text { Aplicar atividade com imagens para } \\
\text { formulação de frases }\end{array}$ & \\
\hline Aplicar atividade oral sem auxílio escrito & \\
\hline $\begin{array}{l}\text { Aplicar atividade de leitura de frases, } \\
\text { mudando-as para formas negativa e } \\
\text { afirmativa }\end{array}$ & \\
\hline
\end{tabular}




\subsubsection{Ações do professor}

É interessante perceber que cada ação praticada pelo professor pertence a algum método ou a alguma abordagem de ensino de LE. Por exemplo, quando o professor utiliza-se do livro didático do curso para realizar exercícios junto com os alunos, os quais, de fato, são baseados em repetição de estruturas gramaticais; logo, conduz a memorização. Isso nos remete ao traço do método audiolingual.

Já, na atividade de exercícios em grupo ou em duplas, pode-se notar que o professor promoveu uma cooperação mútua ao utilizar de técnicas do método CLL. Essa atividade em grupo, também, pode ser entendida como estratégias socioafetivas (BROWN, 2000, p. 126).

Todas as outras ações utilizadas são congruentes ao método direto, que busca focar no uso exclusivo da língua alvo para ministrar a aula, exceto alguns momentos em que o professor fala em LM para explicações a respeito do conteúdo. Ao olharmos atentamente, tais ações é possível perceber que a abordagem do professor é congruente à abordagem comunicativa ou à natural, pois faz com que o aprendizado dos alunos ocorra de forma induzida ou natural. O professor confirmou tal proposição durante a entrevista:

Tento não utilizar a tradução. Mas é um pouco complicado, pois tenho que usar um pouco de tudo. O livro em si aborda tradução, então tento mesclar. Mas gosto que a maior parte da minha aula seja comunicativa, abordagem natural ou direta, que é na língua alvo em si. As técnicas eu uso por associação e durante estas técnicas tem alunos que vão ajudando um ao outro quando um não entende a associação. Associação quanto às coisas do cotidiano ou mesmo palavras e criatividade.

Assim, as ações do professor se sustentam tanto em métodos orientados para a oralidade quanto também em estratégias que possam auxiliar o aprendizado de seus alunos.

\subsubsection{Ações dos alunos}

Ao observarmos as ações dos alunos durante as aulas, podemos reconhecêlas como estratégias para a aprendizagem de LE. Tais estratégias, então, surgiram espontaneamente, ou seja, autônomas, visto que o professor não solicitou determinadas ações. Os alunos as faziam por decisão própria, tais como anotações em seus cadernos, ou perguntas em língua japonesa, ou antecipação para eventuais perguntas orais referentes aos exercícios propostos pelo professor.

Nas ações dos alunos, observamos, também, mais traços do Método CLL e de estratégias de aprendizado. Isso quando eles ajudam uns aos outros, mesmo sem que o professor peça ou incite. Percebemos, também, efeitos do CLL quando eles respondem em conjunto as perguntas orais ao professor. Nesse sentido, é interessante ressaltar que tais ações foram elencadas como um dos pontos que contribuíram para 
a aquisição da oralidade da língua japonesa por parte desses alunos pesquisados. No questionário aplicado, ao perguntarmos o que contribuiu para que falassem em japonês durante as aulas, os alunos responderam, em unanimidade, que a interação com o professor e colegas foi um dos pontos que contribuiu fortemente para que a aquisição da oralidade ocorresse. Esta interação não apenas foi, de fato, observado nas aulas, como também se adequa às estratégias de aprendizado dentro do método CLL, o qual enfatiza a ajuda mútua em classe para se chegar a um determinado propósito, que, no caso do curso de LE, é a aquisição de uma LE.

Por fim, ressaltamos mais um ponto interessante da nossa observação que é: a habilidade oral dos alunos era bem superior que da leitura. Podemos inferir duas causas para essa característica dos alunos. Primeira, o foco das aulas é a oralidade. Mesmo que a leitura fosse trabalhada, a ênfase maior era a habilidade oral. Segunda, a habilidade de leitura não é bem assimilada nesse estágio da aprendizagem. Eles despendem tempo para poder ler um texto curto e compreendê-lo pela leitura. Mas, compreende esse mesmo texto ouvindo e falando, o que pode ser visto nos mais fluentes.

\subsection{Efeitos das técnicas utilizadas pelo professor}

Como visto anteriormente, o professor utilizou mais de um método para aplicar em suas aulas. Embora tenha mantido o Método Direto desde o início do curso, o professor decidiu mudar o método com o objetivo de atender aos alunos que não conseguiam se desenvolver. O próprio professor nos revelou na entrevista essa necessidade:

Precisei mudar os métodos. Eu acho muito divertido aquele outro método (abordagem natural). Ah, eu me sinto tão bem sabe. Porque é um método que mexe com o raciocínio dos alunos. Mas, infelizmente, alguns alunos não estavam acompanhando. Então, tive que mudar um pouco o método por causa do rendimento desses alunos. Eu vi que melhorou bastante (com a mudança de método). Dois alunos que não estavam conseguindo acompanhar, agora estão. Estão indo muito bem. Então, tive que adaptar realmente. Aquele método lá, o natural, direto, ele é... assim... eu tento utilizar quando, por exemplo, tem o momento de falar japonês (utiliza método direto) e de explicação (utiliza método gramatical). Mas houve uma grande diferença. Antes, estes alunos não conseguiam acompanhar e agora estão inclusive participando das aulas."

Apesar da mudança de método diante da necessidade de alguns alunos, a outra parte da turma, que conseguia progredir com o método inicial, não se sentiu desmotivada. Pelo contrário, no questionário, os alunos afirmaram que o uso de ambas as línguas (portuguesa e japonesa) pelo professor os influenciou, positivamente, no aprendizado. Ainda reiteraram que a utilização de gestos e de imagens pelo professor junto com a língua alvo era algo motivador para o desenvolvimento da oralidade. 
Ao final do curso, os alunos relataram sobre sua satisfação de adquirir a oralidade em japonês com o apoio de todos os métodos e técnicas do professor. A fim de averiguar tal afirmação, aplicaram-se dois testes orais - um no primeiro dia de observação e outro no último. Os testes demonstraram positivamente a aquisição da oralidade dos alunos e o melhor desenvolvimento após as mudanças feitas pelo professor.

$\mathrm{Na}$ tabela abaixo, podemos verificar que inicialmente os alunos participantes (apelidados de P1 a P5) possuíam grande divergências de desenvolvimento na aprendizagem. Devido a isso, pode-se inferir que o método inicial só supria a necessidade de alguns. Todavia, no segundo teste, todos apresentaram um nível equiparado de desenvolvimento, o que demonstra que a mudança de método pode ter influenciado, expressivamente, na aprendizagem daqueles que não estavam conseguindo progredir.

TABELA 2 - Resultado da aplicação do $1^{\circ}$ teste oral

\begin{tabular}{|c|c|c|c|c|c|}
\hline ALUNO & $\begin{array}{c}\text { Quantidade de } \\
\text { acertos }\end{array}$ & $\begin{array}{c}\text { Quantidade de } \\
\text { わかりません }\end{array}$ & Equívocos & $\begin{array}{c}\text { Porcentagem } \\
\text { de acertos }\end{array}$ & $\begin{array}{c}\text { Duração } \\
\text { (tempo) }\end{array}$ \\
\hline P1 & 10 & 6 & 0 & $62,5 \%$ & $2^{\prime} 12^{\prime \prime}$ \\
\hline P2 & 14 & 0 & 2 & $87,5 \%$ & $2^{\prime} 14^{\prime \prime}$ \\
\hline P3 & 15 & 0 & 1 & $93,75 \%$ & $3^{\prime} 11^{\prime \prime}$ \\
\hline P4 & 16 & 0 & 0 & $100 \%$ & $1^{\prime} 44^{\prime \prime}$ \\
\hline P5 & 16 & 0 & 0 & $100 \%$ & $1^{\prime} 56^{\prime \prime}$ \\
\hline
\end{tabular}

TABELA 3 - Resultado da aplicação do $2^{\circ}$ teste oral

\begin{tabular}{|c|c|c|c|c|c|}
\hline ALUNO & Quantidade & Quantidade de & Equívocos & $\begin{array}{c}\text { Porcentagem } \\
\text { de acertos } \\
\text { わかりません }\end{array}$ & $\begin{array}{c}\text { Duração } \\
\text { (tempo) } \\
\text { [mesmas do } \\
\text { teste 1] }\end{array}$ \\
\hline P1 & 24 & 1 & 0 & $96 \%$ & $2^{\prime} 00^{\prime \prime}$ \\
\hline P2 & 20 & 2 & 5 & $80 \%$ & $2^{\prime} 37^{\prime \prime}$ \\
\hline P3 & 22 & 1 & 3 & $88 \%$ & $2^{\prime} 19^{\prime \prime}$ \\
\hline P4 & 24 & 1 & 0 & $96 \%$ & $1^{\prime} 35^{\prime \prime}$ \\
\hline P5 & 24 & 0 & 0 & $96 \%$ & $1^{\prime} 29^{\prime \prime}$ \\
\hline
\end{tabular}




\subsection{Desempenho dos alunos nos testes orais}

Analisamos, nesta seção, a diferença do desempenho dos alunos em termos da duração do tempo que levaram para completar os dois testes aplicados durante nossas observações. Ao responder às perguntas durante os testes, observamos uma demora em tempo ${ }^{4}$ que pode demonstrar uma dificuldade e/ou facilidade do processamento cognitivo de cada um dos participantes.

Para a análise, utilizou-se de um teste estatístico para comparar a diferença dos participantes na escala intra-grupal, embora a amostra fosse pequena. No primeiro teste, o resultado do teste-T demonstra uma diferença significativa $(t(4)=9,05, p<$ $0,001, M=134$ segundos, doravante "s"). Esse resultado exprime que há diferenças individuais em termos de aquisição da oralidade do japonês. O teste 2 , do mesmo modo, mantém o mesmo resultado $(t(4)=10,60, p<0,001, \mathrm{M}=250$ segundos).

A partir desses resultados, podemos dizer que, mesmo que o professor aplique um conjunto de métodos para todos os alunos aprenderem o mesmo conteúdo, a característica individual é marcante. Essa característica pode ter relação com diferentes fatores tais como aptidão, histórico familiar (contato com a comunidade japonesa), motivação, investimento individual (tempo dedicado para o estudo do japonês) entre outros que foram constatados também nos questionários aplicados. Assim, identificamos que a aquisição da oralidade do japonês envolve vários fatores intrínsecos e extrínsecos individuais. Isso nos remete à ideia de que a bagagem linguística cultural, psicológica, cognitiva e social que cada um possui é um fator expressivamente influente na aquisição de LEs

Comparando a diferença entre o teste 1 e o teste 2 em termos do tempo despendido, exclusivamente a parte repetida do primeiro teste, constata-se que não houve nenhuma diferença $(t(4)=1,51, n s)$. Mas, a média da duração do teste $2(108 \mathrm{~s})$ tendeu a ser mais curta do que o primeiro (134s). Isso demonstra que o conteúdo aprendido foi fixado durante um mês, com uma leve tendência de acelerar a velocidade de responder às perguntas. Vale ressaltar que é interessante observar, posteriormente, os comportamentos dos alunos: se esta tendência continuará, mesmo adquirindo outros conteúdos mais complexos.

Em relação às notas dos testes, embora tenha revelado uma heterogeneidade dos participantes no primeiro teste, no segundo teste, observa-se uma maior homogeneidade. No Gráfico 1, em que se correlacionam a nota e a duração (tempo) do teste, observa-se uma tendência de que quem consegue uma nota alta responde mais rápido. Desse modo, embora haja diferenças individuais em geral, pode-se concluir, no que diz respeito ao método de análise, que o tempo é um indicador do processamento cognitivo para os alunos responderem às perguntas, como também mostra quem tem dificuldade de produzir respostas.

4 O tempo é, de acordo com a literatura da área de psicolinguística (JUST; CARPENTER, 1980, RAYNER; 1998) e da tradução (JAKOBSEN, 1999; 2002; 2003), um indicativo de processamento cognitivo de informações (escritas). 
O Gráfico 1, abaixo, demonstra a correlação entre a duração do teste com as notas. O eixo X (horizontal) se refere ao percentual de acertos, enquanto Y (vertical) é a duração em segundos dos testes.

\section{GRÁFICO 1 - Correlação entre a nota do teste oral 2 e o tempo despendido.}

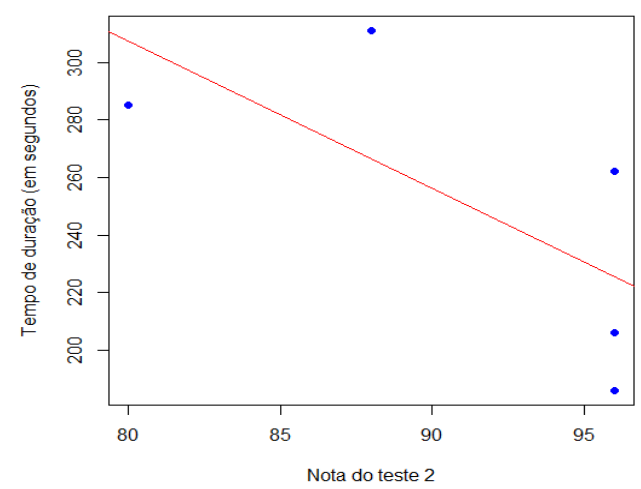

\section{Discussões dos dados}

Ao se observar os dados expostos no decorrer da pesquisa, pode-se notar que determinados comportamentos do professor foram essenciais para ajudar seus alunos a adquirirem a oralidade. Por exemplo, observou-se a atenção do professor quanto a (in) eficácia de seus métodos iniciais e a tomada de decisão para a mudança metodológica com o fito de garantir o desenvolvimento de todos os alunos.

Tais mudanças chegaram ao ponto de motivar seus alunos e de promover um ambiente de aprendizagem mais descontraído. Nota-se que os alunos motivados acabaram se interessando ainda mais em relação ao seu aprendizado, buscando até mesmo outras ações, estratégias em LE (BROWN, 2000, p.122), para alcançarem melhores rendimentos; assim, adquirirem mais autonomia em seus estudos de japonês. Autonomia, essa, que Benson (2002) e outros pesquisadores acreditam ser essencial para o desenvolvimento do aluno dentro de uma LE.

O professor, observado nesta pesquisa, agiu não apenas como facilitador do conhecimento, mas também como instigador dele, o que coincide com os métodos voltados para comunicação mais atuais, em que o professor não possui mais a figura de detentor do conhecimento, mas sim a de facilitador dele. 


\section{Conclusão}

Concluímos com essa pesquisa que a necessidade do professor estar atento à aplicabilidade de seus métodos é um fator importante para a aprendizagem dos alunos. Assim, nota-se que ao se orientar de práticas metodológicas para a necessidade dos alunos, o professor conseguirá atingir seus objetivos dentro de sala de aula, o que respondeu o nosso primeiro questionamento de pesquisa, o qual queríamos observar se as técnicas utilizadas pelo professor geram os efeitos esperados.

Diante da necessidade de mudança metodológica feita pelo professor para auxiliar alguns alunos com dificuldades a se desenvolver, respondeu-se a segunda questão desta pesquisa: o professor varia as técnicas em sala de aula? Sim. Houve a necessidade de variação de técnicas e de métodos para não apenas incluir alguns alunos, mas também para não desmotivar os outros que estavam conseguindo se desenvolver com o método inicial.

Em relação a quais técnicas fizeram com que os alunos conseguissem falar a língua alvo, no caso desta pesquisa, a língua japonesa, chegou-se à conclusão que as atividades em grupo ou em duplas geraram efeitos maiores. As atividades em grupo favoreciam a ajuda mútua entre os colegas e, até mesmo, levavam a estratégias socioafetivas para conseguirem realizar atividades orais propostas pelo professor. A cooperação da turma foi um dos fatores importantes para a aquisição da oralidade e, também, seu desenvolvimento.

Além de responder a nossas perguntas da pesquisa, constatou-se que o professor usa de vários métodos e de técnicas na sala de aula com o intuito de facilitar aprendizagem bem como de manter a motivação dos alunos. Esse uso múltiplo de métodos e técnicas é espontâneo, o qual pode ter uma relação profunda com o tamanho da bagagem que o professor tem por meio de suas próprias experiências como aluno e como professor. Constatou-se, também, que a facilidade da aprendizagem veio com o uso da LM dos alunos pelo professor. Assim, infere-se que, no caso de línguas distintas, a Abordagem Natural e o Método Direto deve ser aplicado com bastante cuidado para assegurar a aquisição dos alunos.

Nosso estudo é exploratório além de ponto de partida para outros desdobramentos futuros. Nossa próxima intenção é replicar a mesma investigação em outros níveis, em que se envolve uma maior quantidade de informações e de conteúdos na aprendizagem em sala de aula. Especialmente, no caso do curso de língua japonesa, o desafio de aprender a leitura e escrita é expressivo. Logo, os alunos têm menos tempo para a prática oral. Será interessante observar alunos de diversos níveis para identificar a dificuldade ou a facilidade da aquisição dessa língua. 


\section{Referências Bibliográficas}

ANDERSON, J. Cognitive psychology and its implications. Second edition. New York: Freeman, 1983.

AUSUBEL, D.P. The psychology of meaningful verbal learning. Oxford: Grune \& Stratton, 1963.

BIALYSTOK, E. A Theoretical model of second language learning. Language learning, vol. 28 -1, 1978. pp. 69-83.

BENSON, P. Defining and describing autonomy. In: BENSON, P. Teacher and describing autonomy in Language Learning. London: Longman, 2001. pp. 47-58.

BROWN, H. D. Principles of language learning and teaching. 4th ed. White Plains: Pearson Longman, 2000. xiv, 356 p.

. Teaching by principles: an interactive approach to language pedagogy. $3 \mathrm{rd}$ ed. White Plains: Pearson Education, 2007. pp. 14-49.

CASTRO, E.C.; GUDWIN, R. R. Memória Episódica em Sistema Cognitivos. In: Encontro dos Alunos e Docentes do Departamento de Engenharia de Computação e Automação Industrial, 2. 2009, Campinas, Anais. São Paulo: UNICAMP, 2009.

ELLIS, R. Understanding Second Language Acquisition. Oxford: Oxford University Press. 1987.

. The Study of Second Language Acquisition. Oxford: Oxford University Press, 1994.

GATTEGnO, C. Teaching Foreign Languages in Schools: The Silent Way. 2nd ed. New York: Educational Solutions. 1972.

HOLEC, H. Autonomy and Foreign Language Learning. Oxford: Pergamon. 1981.

JAKOBSEN, A. L. Logging target text production by Translog. In: HANSEN, G. (ed.), Probing the process in translation: methods and results, Copenhagen Studies in Language. Copenhagen: [s.n.], v. 24, pp. 9-20, 1999.

JUST, M. A.; CARPENTER, P. A. A theory of reading: From eye fixations to comprehension. Psychological Review, v. 87. n.4, pp. 329-354, 1980.

KRASHEN, S. D. Principles and Practice in Second Language Acquisition. Prentice-Hall International, 1987.

. Second Language Acquisition and Second Language Learning. New York: Prentice Hall, 1981.

KRASHEN, S. D.; TERRELL, T. D. The natural approach: Language acquisition in the classroom. Hayward, CA: Alemany Press 1983.

LOZANOV G. Suggestology and Outlines of Suggestopedy. New York: Gordon \& Breach, 1978.

RAYNER, K. Eye movements in reading and information processing: 20 years of research. Psychol Bull, v. 124 (3), pp. 372-422, nov. 1998. 
RICHARDS, J. C.; RODGERS, T. Approaches and Methods in Language Teaching. 2nd ed. Cambridge: Cambridge University Press, 2001.

SHIBATANI M. JAPANESE. In COMRIE, B. (ed.). The Major Languages. Oxford University Press, New York, 1990. pp. 855-880.

VILAÇA, M.L.C. Métodos de Ensino de Línguas Estrangeiras: fundamentos, criticas e ecletismo. Revista Eletrônica do Instituto de Humanidades. vol.7, n.16, 2008. pp. 73-90.

VYGOTSKY, L. S. Mind in society: The development of higher psychological processes. Cambridge, MA: Harvard University Press. 1978. 


\section{APÊNDICE}

PERFIL DO PROFESSOR (com respostas)

1. ANO DE NASCIMENTO

2. SEXO

3. NACIONALIDADE

4. ANOS DE EXPERIÊNCIA EM DAR AULA DE LÍNGUA JAPONESA

5. ÁREA DE FORMAÇÃO

Letras - Japonês (licenciatura)

6. CURSOS FEITO PELO PROFESSOR

Nível avançado em libras

Intermediário de Inglês

Atualmente está cursando Letras - Esapanhol

7. AS AULAS SÃO MINISTRADAS EM LÍNGUA JAPONESA Sim

8. O PROFESSOR DÁ O SIGNIFICADO EM PORTUGUÊS DO QUE FALA UTILIZANDO A LÍNGUA JAPOENESA

Evito ao máximo dar a tradução, fornecendo apenas quando necessária.

9. SE USAAAPOSTILA DO CURSO

Sim

10. SE AS ATIVIDADES SÃO VOLTADAS PARAA ORALIDADE Sim

11. COMO É FEITO O LETRAMENTO DOS ALUNOS Utilizando a língua alvo e a língua portuguesa.

12. OS ALUNOS USAM A LINGUA JAPONESA EM AULA Todos

13. IMPORTÂNCIA DA ORALIDADE EM DETRIMENTO DAS OUTRAS Muito importante

14. COMO É TRABALHADA A HABILIDADE ORAL DOS ALUNOS

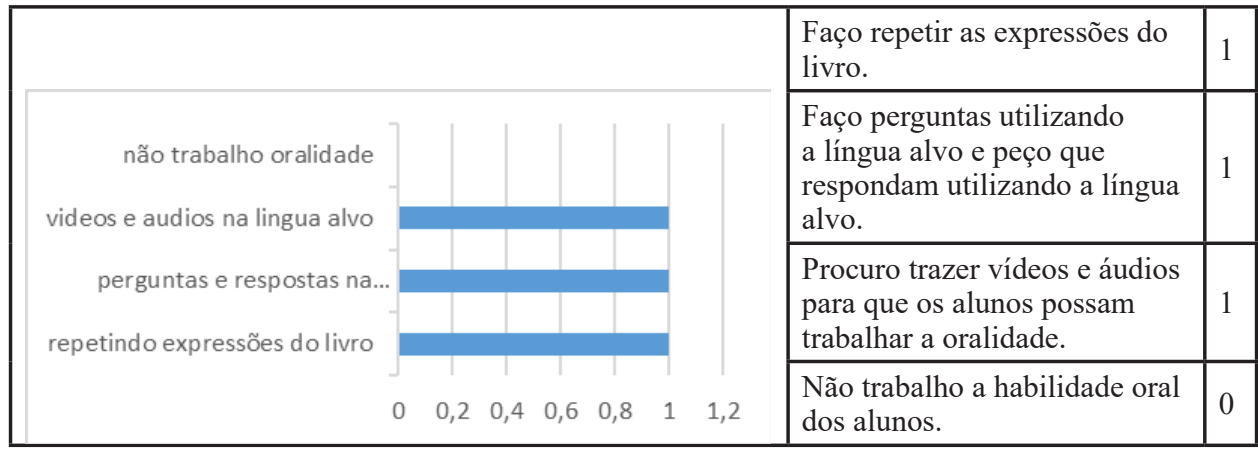

15. SE HÁ ATIVIDADES QUE DESPERTEM O INTERESSE DOS ALUNOS EM FALAR NA LÍNGUA. Nem sempre 
16. O QUE CATIVA A VONTADE DE FALAR NA LÍNGUA ALVO DOS ALUNOS, SEGUNDO O PROFESSOR

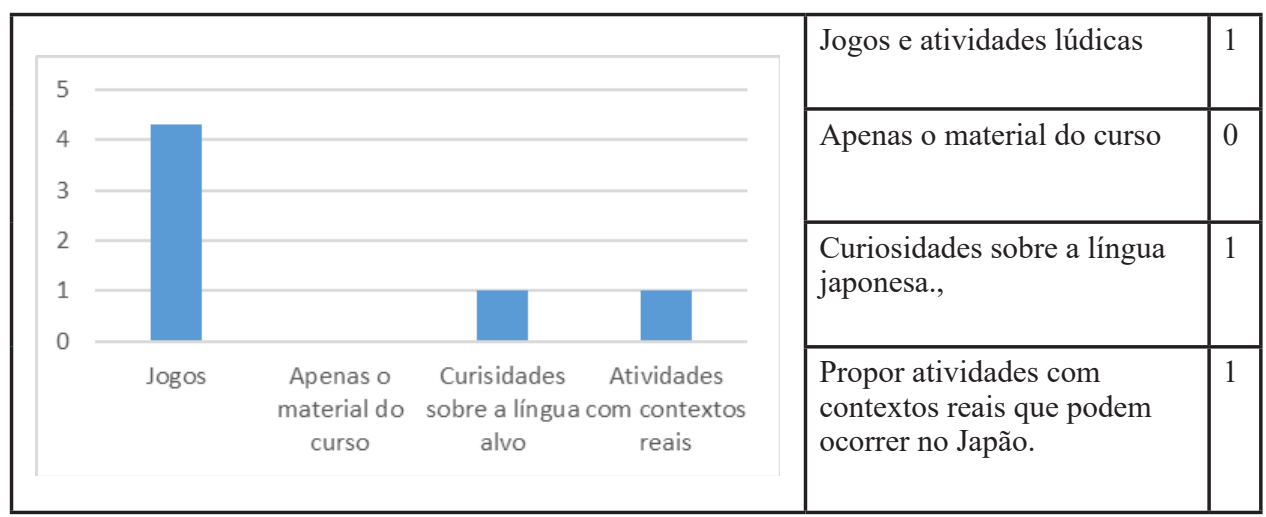

\section{ROTEIRO ENTREVISTA COM PROFESSOR}

1 - Quais técnicas e métodos você usa em sala de aula para aplicar as atividades? Especialmente as que envolvam oralidade e compreensão auditiva.

2- Quais seus instrumentos de ensino? (audiovisual, vídeo, cd,etc...)

3 - Sobre o conteúdo, o que foi passado até então aos alunos?

4 - E o que será passado nas próximas aulas? Num período mais ou menos de 4 aulas (1 mÊs)

5 - E quais são suas expectativas em relação à aprendizagem dos alunos ao final desse período?

\section{QUESTÕES PARA ENTREVISTA DE FINAL DE OBSERVAÇÃO COM O PROFESSOR}

Quais métodos e técnicas o professor utilizou nesse período?

Conseguiu dar o conteúdo conforme programado?

Houve algum aluno que não progrediu mesmo com todos os métodos e técnicas utilizados, como o professor está lidando com estes casos? 


\section{QUESTIONÁRIO SOBRE O PERFIL DOS ALUNOS}

1. Nome:

2. Sexo:

( ) Masculino

( ) Feminino

3. Idade:

4. Cidade (onde mora):

5.

6. Nível de escolaridade:

( )Nível Fundamental Incompleto

( )Nível Fundamental Completo

( )Nível Médio Incompleto

( )Nível Médio Completo

( ) Ensino Superior Incompleto

( ) Ensino Superior Completo

( ) Pós-Graduação Incompleta

( ) Pós-Graduação Completa

7. Ocupação
( ) Estudante
( )Desempregado
( ) Autônomo
( )Empregado de Empresa Pública
( ) Empregado de Empresa Privada
( ) Empresário
( ) Aposentado
( )Outro:

8. Você já estudava a língua japonesa anteriormente?
( ) SIM
( ) NÃO

9. Onde estudava?
( )escola de línguas
( )em casa
( )internet
( )não estudava
( )outro: 
10. Qual seu contato com a língua japonesa? Pode marcar mais de uma opção.
( )internet
( )família
( )amigos
( )escola
( )trabalho
( )outro:

11. Você usa a língua japonesa fora da sala de aula?
() $\mathrm{SIM}$
( )NÃO

12. Você costuma estudar a língua japonesa em casa?

$$
\begin{aligned}
& \text { ( )SIM } \\
& \text { ( )NÃO }
\end{aligned}
$$

13. Você participa ativamente das atividades que envolvam falar na língua japonesa durante as aulas?

$$
\begin{aligned}
& \text { ( )SIM } \\
& \text { ( )NÃO }
\end{aligned}
$$

14. Você costuma assistir a jornal, filmes, animes ou novelas japonesas?
( ) SIM
( ) $\mathrm{NÃO}$

15. Você acredita que praticar a fala na língua japonesa dentro da sala de aula seja importante para adquirir habilidades de comunicação oral (falar) e compreensão auditiva (ouvir)?
( ) SIM
( ) $\mathrm{NÃO}$

16. Caso tenha respondido NÃO, por favor justifique sua resposta:

\section{QUESTIONÁRIO SOBRE A APRENDIZAGEM DOS ALUNOS}

1 -Você aprendeu a falar, mesmo que um pouco, em japonês?
( ) SIM
( ) NÃO 
2- O que mais contribuiu para falar na língua japonesa?

( ) Os exercícios em sala de aula

( ) Estudar em casa

( ) A interação com o professor

( ) A interação com os colegas

( ) A interação com o professor e colegas

( ) O livro didático

( ) Nada

( ) Outros:

3 - A forma como o professor dá as aulas de japonês influenciaram de forma positiva na sua aprendizagem da língua japonesa?
( ) SIM
( ) NÃO

4 - O comportamento do professor com os alunos te incentivava a estudar?
( ) SIM
( ) NÃO
( ) Indiferente

5 - Durante as aulas, o que te influencia mais a aprender a língua japonesa?

( ) O professor utilizar APENAS a língua japonesa para dar as aulas.

( ) O professor utilizar APENAS a língua portuguesa para dar as aulas.

( ) O professor utilizar AMBAS língua japonesa e língua portuguesa para dar as aulas.

6 - Quando o professor fala algo em japonês, você prefere que:

( ) O professor dê de imediato o significado em português.

( ) O professor tente explicar em japonês através de gestos ou imagens.

( ) O professor tente explicar em japonês através de gestos ou imagens, e em seguida dar o significado em português.

7 - Gostaria de continuar a aula de língua japonesa, depois de terminar o curso vigente?
( ) SIM
( ) NÃO
( ) Indiferente 
8 - Até agora, as aulas são divertidas?
( ) SIM
( ) NÃO
( ) Indiferente

9 - Até agora, o conteúdo das aulas é adequado?
( ) SIM
( ) NÃO
( ) Indiferente

10 - Até agora, você está satisfeito com as aulas?
( ) SIM
( ) NÃO
( ) Indiferente

11 - Escolhe apenas UM objetivo mais próximo do seu para você cursar a língua japonesa na UnB Idiomas.
( ) Curiosidade
( ) Necessidade (viagens, negócios, entender manuais, instruções ou filmes etc.)
( ) A fim de estudar na faculdade futuramente
( ) Sem motivo específico
( ) Outros

\section{TESTE Oral 1 com transcrição de respostas do Aluno 1}

1. ENTREVISTADOR - おはようございます。はじめまして、私は[nome do entrevistador]です。 じうぞよろしくお願いします。

あなたはDARCY RIBEIRO さんですか。

GB 1 - いいえ、わかりません。

2. ENTREVISTADOR一おなまえはなんですか。

GB 1 一わたしはFulanoです。

3. ENTREVISTADOR -あなたは先生ですか。

GB 1ーいいえ、Ciclanoです。

4. ENTREVISTADOR一あなたは 学生ですか。

GB 1 一わかりません。

5. ENTREVISTADOR -あなたは日本人ですか。

GB 1 一わかません。 
6. ENTREVISTADOR - あなたはアメリカから来ましたか。

GB 1 一いいえ、ブラジルから来ました。

7. ENTREVISTADOR - Ciclanoさんはあなたの先生ですか。

GB 1 一わかりません。

8. ENTREVISTADOR - これは本ですか。

GB 1 ーわかりません。

9. ENTREVISTADOR一これはなんですか。 (entrevistador se refere ao próprio computador em cima da mesa)

GB 1 ーコンピューターです。

10. ENTREVISTADOR - このコンピューターはあなたのですか。

GB 1 一わかりません。

11. ENTREVISTADOR -これはブラジルですか。(entrevistador mostra uma figura sobre o Brasil) GB 1 一はい。

12. ENTREVISTADOR - これはアメリカですか。(entrevistador mostra uma figura sobre o Japão)

GB 1 -いいえ。

13. ENTREVISTADOR - Ciclanoせんせいは日本人ですか。

GB 1 ーいいえ。

14. ENTREVISTADOR -それは日本人ですか。(entrevistador mostra uma figura de japoneses)

GB 1 一はい。

15. ENTREVISTADOR -それは[nome da universidade]ですか。 (entrevistador mostra uma figura do campus da universidade)

GB 1 一はい。

16. ENTREVISTADOR- 終わりました。本当にありがとうございました。 


\section{TESTE Oral 2 com transcrição de respostas do Aluno 5}

1. ENTREVISTADOR - おはようございます。私は[nome do entrevistador]です。

2. ENTREVISTADOR - あなたはDARCY RIBEIRO さんですか。 GB - いいえ、DARCY RIBEIROじやありません

3. ENTREVISTADOR - お名前はなんですか。 GB - わたしはBeltranoです。

4. ENTREVISTADOR - あなたは先生ですか。 GB - はい、せんせいです。

5. ENTREVISTADOR - あなたは学生ですか。 GB - はい、わたしはがくせいです。

6. ENTREVISTADOR - あなたは日本人ですか。 GB - いいえ、わたしはブラジルじんです。

7. ENTREVISTADOR - あなたはアメリカから来ましたか。 $\mathrm{GB}$ - いいえ。

8. ENTREVISTADOR - Ciclanoさんはあなたの先生ですか。 GB - はい。

9. ENTREVISTADOR - これは本ですか。

GB - いいえ、それはパソコンです。(resposta completa, sendo desnecessário fazer a pergunta a seguir) 10. ENTREVISTADOR - これはなんですか。（コンピューター）

$\mathrm{GB}$ - [Essa pergunta não foi dada, visto que o entrevistado já respondeu na pergunta anterior.] 11. ENTREVISTADOR - このパソコンはあなたのですか。(entrevistador se refere ao próprio computador em cima da mesa)

$\mathrm{GB}-$ いいえ。

12. ENTREVISTADOR - これはブラジルですか。( imagem do Brasil) GB - はい。

13. ENTREVISTADOR - これはアメリカですか。（imagem do Japao） GB - いいえ。

14. ENTREVISTADOR - Ciclanoせんせいは日本人ですか。 GB - いいえ。

15. ENTREVISTADOR - それは日本人ですか。(imagens de japoneses) GB - はい、にほんじんです。

16. ENTREVISTADOR - それは[nome da universidade]ですか。（foto da universidade） GB - はい。 
17. ENTREVISTADOR - これはきゅうですか、ろくですか。 (entrevistador mostra imagem do número 9)

$\mathrm{GB}$ - きゅう。

18. ENTREVISTADOR - この本はえいごのほんですか。（imagem de um livro de japonês）

GB - いいえ、にほんごのほんです。

19. ENTREVISTADOR - このでんわはだれのですか。(imagem de um telefone)

GB - fulanoさんのです。

20. ENTREVISTADOR - あなたはなんのがくせいですか。

GB - にほんごのがくせいです。

21. ENTREVISTADOR - あなたはなんさいですか。

$\mathrm{GB}$ - わたしはごじゅうよんさいです。

22. ENTREVISTADOR - Ciclanoせんせいはあなたのえいごのせんせいですか。

$\mathrm{GB}$ - いいえ、にほんごのせんせいです。

23. ENTREVISTADOR - これはコンピューターですか、テレビですか。(mostra imagem com televisão)

$\mathrm{GB}$ - テレビです。

24. ENTREVISTADOR - このテレビはいくらですか。(mostra imagem com preço \$ 2.150)

$\mathrm{GB}-$ にまんじゅうごせんえんです。

25. ENTREVISTADOR - このテレビはどこからきましたか。 (imagem que mostra de onde a televisão veio)

GB - にほんからきました。

26. ENTREVISTADOR - このテレビはテレビのアメリカですか。

$\mathrm{GB}$ - いいえ。

27. ENTREVISTADOR - 終わりました。本当にありがとうございました。 